\title{
The paradox of gender equality in the arena of cultural beliefs and practices of the people of Kasena Nankana Municipality.
}

\author{
Victoria Mensah Nyamadi (Corresponding author) \\ Christian Service University College, Kumasi, Ghana. \\ Email:vmensah@csuc.edu.gh, awotwe2001@yahoo.com \\ Telephone: +233 201852 363, +233244202367 \\ Gideon Atigetogum Affah \\ Navrongo Health Research Centre, Navrongo, Ghana. \\ Email: atigzi2005@gmail.com \\ Telephone: +233201037 403, +233243559160 \\ Russell Franklin Nyamadi
}

Institute of Distance Leaming, Kwame Nkrumah University of Science and Technology (KNUST), Kumasi, Ghana. Email: kojoruss@gmail.com

Telephone: +233508590491, +233268 816900

*Email of Corresponding Author: vmensah@csuc.edu.gh, awotwe2001@yahoo.com

Telephone: +233 $201852363,+233244202367$

\begin{abstract}
Gender equality is a very common mantra in gender studies but its importance can be undermined. Gender stereotypinghas characteris ed social value in many communities of the north. The focus of this study has been to examine how cultural practices and beliefs in the patrilineal family system dominated by male discriminate against women and female children.

Through well-defined research objectives, the study unveiled how cultural practices and beliefs in the Kasena Nankana Municipality impact on gender equality and further marginalize the women in the communities.

The study's main finding was that; gender inequalities still pertains in the study area and this is due to cultural ascription of gender roles. The study further highlighted that, gender socialization perpetuates society's expectations of what a woman supposed to do in the societies. The behaviours and attitudes of the women in the communities were also considered under the study to determine whether these behaviours contributed to gender inequality in the communities.
\end{abstract}

Key words: Gender Equality and Equity, Women's Right, Gender Discrimination, Patriarchy, Culture

\section{Council for Innovative Research}

Peer Review Research Publishing System

\section{Journal: Journal of Social Sciences Research}

Vol. 9, No. 3

jssreditor.cir@gmail.com

www.jssronline.com 


\section{Introduction}

Njogu\&Orchardson-Mazrui ( $\mathrm{n}$ a) in their study said Africa is faced with numerous problems including gender inequalities and these problems exist as a result of global advancement in science and technology while others may be blamed on cultural practices. They also recognized the fact that, there are numerous cultural practices that require immediate eradication. However, it is vital to appreciate that there are useful ones as well. Considering the causes of low enrolment in school, Christopher, et al, ( $\mathrm{n}$ a) in their working paper on gender inequalities in primary schooling said that poverty at both national and household levels accounts for the low enrolment of children of school going age in developing countries but when it comes to gendered causes of low enrolment, it is the product of cultural practices rather than poverty. Their paper revealed that adverse cultural practices impede the attendances and the performances of girls at school as compared to the boys. It is therefore, obvious that even if income levels are bettered in these regions, gender disparities will still be prevailing. Christopher et al $(n$ a) said, a girl's allegiance after marriage is mainly to her husband's family; therefore, her parents will be reluctant to invest in her education while her brothers are there. DISCAP (2002) argues that, gender disparities in educational sector are especially widened in the northern parts of Ghana. The report further revealed that gender bias against girls exist where there is a greater willingness of parents to invest in boy's education over girls due to traditional customs and norms. UNFPA, (2008) also reports that, of the 960 million adult in the world who cannot read, two thirds are women. This goes to reinforce the fact that girls stand disadvantaged to their male counterpart when it comes to making choices between the two.

The three northem regions of Ghana are said to be flooded with several ethnic groups and for that matter numerous cultural values and noms shaping the conduct of gender behaviours. For Njogu\&Orchardson-Mazrui, ( $n$ a) through culture we are able to see society in its strength and weakness and also to see ourselves. Unfortunately the prevalence of the Patrilineal customary system in the northern part of Ghana provides no direct protection for women's right according to report by District Capacity Building Project (DISCAP, 2002). The report gave an example to be the dowry systems that makes the wife the property of the husband thereby giving the man the right to use her as a labourer.

Available literature suggest that, culture ideological systems have created gender stereotyping in the societies, where women are seen as subordinates and men dominating in all levels in the household, however according UNDP (2003), gender equality is first and foremost a human right. Women are entitled to live in dignity and in freedom and from fear. Hence giving women full participation on the basis of equality in all walks of life especially participation in decision making process and access to economic power.

\section{Brief description of the study area}

Kasena Nankana Municipality is a Bi-lingua area, Kasem and Nankam. The Kasem speaking communities dominate the western part of the municipality, while the latter dominates the southern part of the municipality. The municipal population is estimated at 157,000 people where $90 \%$ of them are rural inhabitants (NHDSS, 2013). The Populace are culturally oriented and "Fao" is the most celebrated festival in the municipality and most of their fam products go into the preparation of traditional dishes during funerals, festivals and other important occasions.

According to Ghanadistrict.com, (2014), KNM municipality is one of the thirteen (13) municipalities and districts in the Upper East region. The municipal administrative capital is Navrongo, an important market town servicing as a hub to the surrounding districts and towns. Ghanadistrict states that, the KNM municipality lies within the Guinea Savannah woodlands and it falls approximately between latitude $11^{0} 10^{1}$ and $10^{0} 3^{1}$ north and longitude $1^{0} 5^{1}$ and $10^{0} 1^{1}$ west. The municipal assembly shares boundaries with Bongo district and Bolgatanga municipality to the East, West Mamprusi to the south and to the west with Builsa south District and Builsa Central District. Finally the KNM Assembly shares boundaries with Burkina Faso to the North.

Subsistence level of agriculture is the usual occupation of the populace in the wet seasons and in the dry seasons through irrigation. The rearing of goats, guinea fowls and cattle is also common in the municipality. The southem part of the municipal is densely vegetated around riverbanks and the forest reserves of Kologo and Naga. The commonest trees are the Dawadawa, the Baobab, the Shea tree and the Mango tree. The wet season starts from May to October and it is characterized by heavy rainfalls averaging $950 \mathrm{~mm}$ as myweather2.com puts it. There is a dry season spanning from November to April. Weather data reported by myweather2.com shows that, the local average high temperature per annum is $35.3^{\circ} \mathrm{C}$ and lowest average temperature per annum is $22.7^{\circ} \mathrm{C}$, (Ghanadistrict.com, 2014)

\section{Data and method}

Given the priority of the topic under investigation, the study made used of a Cross sectional research design. Understanding the behaviours and attitudes of the respondents under different cases in the study was very paramount. Focus Group Discussions (FGDs) were conducted with Women's Groups Leaders, Beneficiaries of gender intervention programs, and Community Leaders (Assembly men or Assembly women or Chiefs), Coordinators of NGOs in gender equity and women empowement, Social Welfare Officers in the Municipality and Gender Activists. These groups also formed the participants for the in-depth interviews; Women with formal education (above primary school), Grandmothers, Women without formal education and Household heads.

The municipal has been divided into five zones by Navrongo Health Demography Surveillances System (NDSS). Under the zones are communities and the system has further divided each zone into clusters. NHDSS monitors about 32000 households under all the five zones. The sampling procedures combined both random and convenient sampling techniques. NHDSS was instrumental in the selection of participants for the interviews during the fieldwork. Three (3) of 
the five (5) zones were chosen for the fieldwork. The central zone was purposively sampled because it contained the urban communities; this was done to maximize the variability in the understanding of the research topic by the urban folks as against the rural folks. The South and West zones were also randomly selected, one from each group that is the Kasem speaking communities and the Nankam speaking communities. In all the three zones selected, 21 clusters were randomly picked for the interviews and discussions. Not more than one interview or discussion was done in a cluster. The idea was to have independent responses from respondents.

In all, 9 in-depth interviews were conducted where 2 interviews with women's group leaders, 2 interviews with community chiefs, 1 with an assembly man, 1 with an assembly woman, 1 interview with the municipal gender desk officer and2 interviews with social work officers.

The minimum number of participants for a discussion was 6 and maximum was 8 . In all 13 FGDs were held with 2 groups of men and 11 groups of women. Male respondents were grouped separately from female respondents.

Municipal gender desk officer, Community chiefs, Assembly man, Assembly woman, Social work officers, Women's group leaders were purposively selected from the Study area. Women with formal education (above primary school), Grandmothers, Women without formal education and Hous ehold heads on the other hand were randomly chosen.

In-depth interviews (IDIs) were one-on-one basis between the researcher and a participant. Interviews were in the form of semi-structured instrument and detailed probes to guide the discussion. The interviews occurred mostly in respondents' homes and in the office setting (for the NGO advocate, Gender officer and the Social Work officers). Interviews lasted between 25 to 30 minutes.

Focus groups discussions were conducted with 6-8 participants each, typically gathered in a semi-circle around the interviewer. Questions were posed to the group, and the interviewer took responses from participants one by one, moving the hand-held microphone closer to the respondent who was speaking. FGDs also lasted between 45 to 50 minutes to complete.

All interviews and discussions were audio recorded, and notes were kept on verbal and non-verbal communication by a second field team member present at each interview. Interviews and discussions in communities were conducted in the respondent's native language (either Kasem or Nankana) and the rest in English.

Permission to conduct the study in the community was sought from compound or community leaders. Participants were consented, the purpose and objective of the study made known to them before interaction. Each participant was assigned a unique ID number for the purpose of the data. Participants were not offered any monetary incentive for participating in the study. However a cake of soap was given after the discussion.

All interviews and discussions including the pre-test ones were tape-recorded, transcribed verbatim into English and typed. After the transcription each interview was coded under the various themes that emerged during field work. In addition, field notes taken on the field werefactored in analysis.

\section{Results and Discussions}

\subsection{Demographic Data of Respondents}

As part of the data collection exercise on the field, essential infomation about the respondents were collected. This gave sufficient information about the sampled population and it will also guide readers to know the sort of people that were studied as they explore the findings of the study. Information on occupation, marital status, age, sex, education and nativity / Domicile status were collected.

Out of the one-hundred and ten respondents, 18.8 percent of them were identified to be under 30-39 years whereas about 41.82 percent of remaining respondents were between $40-49$ years old. A further 41.82 percent of respondents were between 50-59 old as compared with 12.73 percent of respondents identified to be between 60-69 years old.

The study also collected information concerning the marital status of the respondents in which about 18.8 percent of respondents were unmarried as compared with about 81.82 percent of remaining respondents who were married. Next, most of the respondents admitted that apart from their official occupation, farming also took most of their time. Ten (10) women responded that they were fully into "pito" brewing business while twenty (20) of the other women were engaged in petty-trading. Out of the ninety (19) grandmothers spoken to, twelve said they were not engaged in any activity whereas seven (7) said they help in panting and also collecting shea-fruit during the shea season.

\subsubsection{Sex Composition}

One major feature of the respondents in the study was their sex classification. Considering the rese arch topic, it was necessary to explore the biological make-up of the respondents since sex classification was a pre-condition basis for gender status.

Table1.Sex Composition of Respondents

\begin{tabular}{|l|l|l|}
\hline Sex & Frequency & Percentage \\
\hline Male & 25 & 22.73 \\
\hline
\end{tabular}




\begin{tabular}{|l|l|l|}
\hline Female & 85 & 77.27 \\
\hline Total & 110 & 100 \\
\hline
\end{tabular}

Source: field work, (2014)

Table 1.above shows the sex distribution of respondents involved in this study. The total number of respondents were 77.27 percent females as compared with 22.73 percent of remaining respondents been males. The trend in the sex disparity of respondents was based on the fact that the study wanted to investigate the assertion that "the prevalence of patrilineal customary system in the northem regions of Ghana has no protections for women's right" (DISCAP, 2002). However, this was not done with any bias reservation against the sex of the respondents but as a demand of the study.

\subsubsection{Native/ Domicile status of respondents}

Information about native status or the number of years they resided in the community was taken as part of respondent's vital information. The purpose of this information was to investigate respondent's familiarity, knowledge and understanding of the social issues and cultural practices or beliefs in the community. There were varied responses or information concerning the number of years of domicile or native status in the community. Apparently, eighteen (18) of the respondents were not natives of the land (the municipality) but have stayed in the municipality for more than fifteen (15) years. Affiliation of eleven (11) of the non-natives were through marriage and the rest of the eighteen (18) was through their business engagement in the municipality. Twenty-five (25) of the respondents though natives of the land they have ever stayed outside the municipality. The third category was those who were natives of the land and have never lived outside the municipality since birth and they were sixty-seven (67) in number.

Table 2. Native / Domicile Status of Participants

\begin{tabular}{|l|l|l|}
\hline Domicile status & Frequency & Percentage \\
\hline Native (Never stayed outs ide the Municipality) & 67 & 60.9 \\
\hline Native ( Ever stayed outs ide the Municipality) & 25 & 22.7 \\
\hline Non Native (Stayed in the Municipality for 15 years) & 18 & 16.4 \\
\hline Total & $\mathbf{1 1 0}$ & $\mathbf{1 0 0}$ \\
\hline
\end{tabular}

Sources: Field work, (2014)

From table 2, the greatest proportion of the study's participants were made of people who are natives of the study area who have never stayed outside the municipality before and they formed 60.90 percentage of the total number of participants. These natives supposed to be the true witnesses of the cultural practices and beliefs in the community. On the other hand, natives of the municipality who have ever stayed outside formed 22.70 percent of the study's participants. Finally, the third portion of the participants is made up of the participants who are not natives of the municipality but have stayed in the study area for some time and they represent 16.40 percent of the total number of the participants in the study.

\section{2.Discrimination of women in Kasena NankanaMunicipality}

This section of the study looks at responses that sought to address why most women in Kasena Nankana Municipality suffer discrimination from cultural practices. First of all, the question of whether there exists gender discrimination was posed. Gender discrimination here refers to a situation where women are not treated as equal as men in the face of culture practices and beliefs. An open-ended question was asked and then depending on whatever responses that came out, the respondents were asked to give reasons why they think gender discrimination exist or does not exist. This question was very fundamental to the study and therefore its investigation was necessary.

Analysing the Focus Group Discussions revealed that, nine-two (92) participants out of the 101 participants in the Focus Group Discussions responded to the question whetherwomen were been discriminate against or not. This 92 figure had 75 percent participants responding categorically that, there were some forms of gender discrimination against women. However, 25 percent of the remaining respondents were not definite with their responses, they said there was discrimination in the communities but it was only in some few cases.

Responses gathered during the in-depth interviews conducted were not different from that of the focus groups discussions. In the nine (9) in-depth interviews conducted, 89 percent of the interviewees admitted that women were being discriminated against in the municipality. However, one (1) interviewee representing the 11 percent was not also definite with his responses. He said yes to the question, but quickly added that women were only discriminated against in some few cases.

Information picked from both the interviews and the discussions on why women were being discriminated against revealed that; first and foremost, community members have the belief that men and women do not have the same social status and therefore, women cannot be treated as equal as men in the society. Respondents said from time immemorial and at the time of their ancestors, women were not allowed to sit and part take in household discussions and decision making because women by nature cannot keep secrets and because of this reason, women were not called upon to partake in discussions in the house concerning issues of the house. According to the discussions, women are not part of the families 
in the house until they have given birth to up to three children. There are several things in the house women are not allowed to do like participation in major family discussions. The belief is that once the woman has not given birth, the tendency for her to break out of the marriage is high and once she has the secrets of the house she can spread it. Girls are also discriminated against because one day they will marry and end up belonging to th eir husbands.

A woman in one of discussions asserted that:

"Because, the girl will marry in future, they will take care of the boy and leave the girl" (FGD - Women with Empowerment -J-Kasem Community).

Men use their physical strength to bully and dominate the women in the Municipality thereby depriving them of so many things in the communities. This was evident in an interview with one of social welfare officers on the field in the Municipality.

In an interview, a social worker said:

"By nature men are physically stronger and therefore they use their physical strength to dominate the women" (IDI-Social Welfare Officer-1)

The fifth (5) respondent in a group discussion also put it in this way;

"In the olden days men always override women" (FGD - Household Heads - G -Kasem Community)

Another reason given for the discrimination was that, men were the owners of the house and their sons will also succeed them and for that matter men or male children have a lot of stake in the house than the women or female children. The biological make -up of women such as pregnancy do not allow them to take part in certain activities in the communities. Through the customary systems, once the man goes to marry the woman from her father's house, the woman becomes the man's responsibility. It also came out from the respondents that the discrimination against women was a generational thing, once women were being discriminated against in the beginning by their ancestors; it has become the order of the day in the communities. Interestingly, one participant in one of the discussions gave his reason by quoting from the Bible. He used the creation of man to explain his point.

"God created man before creating the woman and God gave man the power to oversee everything including the woman" (FGD-Household Head-G-Kasem Community).

The following were given as situations in which the woman was segregated or discriminated at in the communities; Women are not allowed to take part in decision making process in the house, Male children are favoured over female children when it came to resources constraint in education and this cause male dominancy in education, Women are not allowed to consult fetish priest or any spiritual person concerning the family, that role is reserved for the men. Women are not supposed to have any spiritual protection apart from that of her husband. Women do not host visitors in the presence of the husband or in his absence, Women do not take or make decisions for the family and finally during funerals women are not allowed to perform any function outside the compound.

Delving more into the issue of disparity between the women and men revealed that, from the respondents, most of the disparities were coming from cultural practices and beliefs of the respondents' whiles in few cases, it was also attitudinal Compiling the responses from the causes of gender discrimination in the communities of study yielded ninety (90) responses from the group discussions and nine (9) from the in-depth interviews. The ninety (90) responses in the discussion had seventy-six (76) responses that admitted that cultural practice was a factor of the discrimination. Fourteen (14) revealed other factors such as religion and age apart from culture that also contributed to the gender discrimination. All the nine (9) responses from the interviews also confirmed that cultural practices and beliefs were the main causes of gender discrimination in the communities of study.

The Figure 4.1 below shows the cause s of gender discrimination in the communities.

Figure 4.1Causes of Gender Discrimination

\section{Percentage}

- Cultural Practices and Beliefs $\quad$ Others

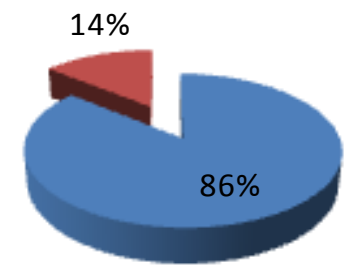

Source: Field work, (2014) 
From the figure 4.1, out of the total responses gathered both from the discussion and the interviews, $86 \%$ gave culture practices and beliefs as been the cause of gender discrimination in the communities while $14 \%$ of the responses gave other factors apart from cultural practices and beliefs as the cause of the discrimination in the communities.

It is obvious from the responses that gender discrimination is prominent among communities of KNM considering the definition of gender discrimination given in chapter two by Reeves and Baden (2002). These findings also confirm the assessment done by Njogu and Orchandson-mazriu ( $n$ a), that Africa is faced with numerous problems including gender inequalities and these problems are blamed on cultural practices. The study confims that culture is a requisite implication of power and a control mechanism which allow for the exploration of gender inequality and this was how Geertz (1973) described culture. This control mechanism became evident in the customary system surrounded by cultural beliefs.

A response from a woman in one of the discussion stated this:

"Because the man brought you the woman to his house and for that matter, you do not have to sit and discuss issues concerning the house with him" (FGD-Women with Education -S-Kasem Community).

This is what a male respondent also said:

"it is the man who goes to bring the woman to his house so the man has control over the woman" (FGD- Household Heads-G-Kasem Community)

The reason is that once the man has gone through all the traditional requirements expected of him to marry a woman, the culture gives him total control over the woman after the bride price is paid.

This assertion came from a participant during a discussion:

"What is there is that, once $\mathrm{i}$ have gone through the marriage procedures and paid her bride price, her people know that she is under my control and once she is under my control, the father does not own her again. I now own her so everything about her is under me" (FGD-Hous ehold Heads-G-Kasem Community).

It was clear that the prevalence of the patrilineal customary system in the communities did not provide any direct protection for women's right as argued by DISCAP (2002). The findings from the field work also confim what Christopher et al ( $n$ a) put up in their working paper. It came out that boys were favoured over their girls' counterparts when it came to spending the family's resource on education.

A fifth female respondent in a discussion made this assertion;

"yes, there is a big disparity between boys and girls, they send the boys to school and leave the girls and say it is the boy that will come and build the house of his father, the boy will one day own the house and keep the family's name for the next generation so that the house will not fall, but for the girl, the girl is going to build someone else house with her children. That is why the fathers do not take the girls to school" (FGD-Women with Education-S-Kasem Community).

In an interview with one of the social welfare officers, he also confimed that girls are not given the chance to go to schoo I as compared to the boys.

"Sometimes in terms of education, you will see that men are dominating" (IDI-Social Welfare Officer-2)

People in the study area believe that once you educate a girl she will end up going to the husband's house to benefit the husband and she will not be of benefit to the father, so they do not see the need to educate the girl child. The question is how does culture and the tradition contribute to this situation. When a prospective husband is able to go through all the traditional marriage proceeding, the woman becomes completely the husband's responsibility. The father of the woman has no control again on the daughter.

\subsection{Women's behaviours that contribute to gender inequalities.}

Investigating the phenomenon that "women are their own enemies" was an objective the study sought to build literature on. The study, however, could not find available literature on the phenomenon to review therefore its investigation was given a peculiar attention.

Participants responded to questions conceming women's behaviours or actions that contribute to gender inequalities in the communities. Responses gathered suggested that, there are actions from the part of women that contributed to the wide discrimination between the men and the women in the communities. Respondents described women's behaviour such as gossiping, envy, adultery and alcoholism as actions that widen the discrimination gap between the men and the women and also impede their empowerment. They said the few women who try to stand tall in the mix of men in the communities are described as "too knowing women or women men" by their fellow women. Respondents added that due to the back-biting attitude; those women who are able to sail through the male dominancy and finally become empowered do not give recognition to their fellow women.

An assertion by a social worker:

"yes but when she sees her fellow women, she does not value them and they are the ones people call too knowing women"(IDI-Social Welfare Officer-1-KNM)

It also came out that, female political aspirants do not even get vote from most of their fellow women when they contest in any election in the communities. When a woman sees her fellow woman progressing due to envy, she will try all possible 
means to bring her down. In an interview with the municipal gender officer, she said, she does not believe that women are their enemies but she sees it happening in the communities. She mentioned that, the issue is about how women were brought-up culturally and socialized to believe that the woman is a subordinate to the man. However she mentioned that, some of these actions are not engineered by the women themselves. The women are being spoken to by their husbands in the rooms and when they come out due to fear of victimisation, the women cannot do contrary to what they have been instructed to say by their husbands. She added that some of the inhuman cultural practices and beliefs are administered by women. There are situations whereby the old women in the communities are involved because they believe that, that is their way of life and that is how a true native woman must live her life. In the case of widowhood rites, it is the old women who force the women to undergo the inhuman widow rite.

An assertion from the gender officer:

"There was a case where a male staff of the Municipal Assemble lost his mother in-law and his wife was made to go through some rituals by the old ladies in the town, but the man stood on his grounds to prevent the wife from going through inhuman rite. The old women wanted the woman to strip nude and follow the dead body. So some time the women too especially the old women are involved" (IDI-Gender Activist-KNM).

Most participants believe that "the women are their own enemies' phenomenon" actually works and it is evident in the municipality. Women participants spoken to also confirmed it and they said until women change some of their own behaviours, they will always fall prey to male dominancy in the communities.

\section{Conclusion}

Undoubtedly, cultural practices and beliefs are major challenges in the development of women issues. Most importantly in the patrilineal family system, it becomes a bottle neck in the liberation of women's right. In the case of KNM, a pure patrilineal system, male supremacy and dominancy is paramount and the fact that these gender powers are rooted in the culture practices and beliefs it is extremely difficult for emancipation.

However, in this era of globalization, women can see liberation from cultural practices and beliefs but this may not come as fast as possible since culture is more or less attitudinal and it takes time to change people's attitude and perceptions. Societies can experience development if this development is a holistic and all-inclusive one.

Culture emancipation is necessary for the development of women in the face of sustainable development. Policies and programs should involve all the stakeholders in the communities including women. However in KNM communities, cultural practices and beliefs are impeding the participation of women in decision making process hence, making policies not all inclusive.

\section{Reference}

Christopher Colclough, Pauline Rose, Mercy Tembon ( $n$ a), Gender Inequalities In Primary Schooling :The Roles of Poverty and Adverse Cultural Practice, Ids Working Paper 78.

Dis trict Capacity Building Project-DISCAP (2002), Gender Analysis and Strategy [Accessed on 26/09/2013]

Ghanadistrict.com [accessed on 9/04/2014]

Kimani Njogu\& Elizabeth Orchardson-Mazrui (n a), Gender Inequality and Women's Rights In The Great Lakes: Can Culture Contribute to Women's Empowerment?

Profile of the Navrongo Health Demographic Surveillance System (NHDSS,2014)

Reeves, H., \& Baden, S. (2000). Gender and Development: Concepts and Definitions. Brighton, UK: Institute of Development Studies, University of Sussex (No. 5). Report.

UNDP (2003), Millennium Development Goals: National Reports a Look Through a Gender Lens.

UNFPA (2008), the State of World Population: Negotiating Culture, Promoting Gender Equality and Empowering Women.

Myweather2 (2013); Navrongo weather averages (myweather2.com) [Accessed on 9/04/2014] 